\title{
Characterization of Ethyl Violet Adsorption on Used Black Tea Leaves from Aquatic Environment: Kinetic, Isotherm and Thermodynamic Studies
}

\author{
Rasel Ahmed ${ }^{1}$, Santa Islam², Mohammad Abul Hossain ${ }^{2, *}$ \\ ${ }^{1}$ Department of Chemistry, Pabna University of Science and Technology, Pabna, Bangladesh \\ ${ }^{2}$ Department of Chemistry, Faculty of Science, University of Dhaka, Dhaka, Bangladesh \\ Email address: \\ hossainabulm@gmail.com (M. A. Hossain),hossainabul@yahoo.com (M. A. Hossain) \\ *Corresponding author
}

To cite this article:

Rasel Ahmed, Santa Islam, Mohammad Abul Hossain. Characterization of Ethyl Violet Adsorption on Used Black Tea Leaves from Aquatic Environment: Kinetic, Isotherm and Thermodynamic Studies. American Journal of Physical Chemistry. Vol. 10, No. 2, 2021 , pp. 31-40. doi: $10.11648 /$ j.ajpc.20211002.14

Received: May 28, 2021; Accepted: June 15, 2021; Published: June 23, 2021

\begin{abstract}
Ethyl violet (EV) is one of the common pollutants in industrial wastewaters. This study presents the kinetic, isotherm and thermodynamic characterization of the adsorptive removal of EV from aqueous solution by used black tea leaves (UBTL) as a low cost adsorbent. Batch adsorption experiments were performed to investigate the effects of initial dye concentration, solution $\mathrm{pH}$ and temperature on the adsorption kinetics. Experimental data were evaluated by inspecting the liner fitness of different kinetic model equations such as pseudo-first order, pseudo-second order, Elovich and Intra-particle diffusion models. The equilibrium amounts adsorbed at different equilibrium concentrations were determined from well fitted pseudo-second order kinetic plot to construct the adsorption isotherm. The maximum adsorption capacity, $q_{\mathrm{m}}=91.82 \mathrm{mg} / \mathrm{g}$ was determined from the well fitted Langmuir plot compared with Freundlich and Temkin plots. Thermodynamic parameters such as free energy change $\left(\Delta G_{\text {ads }}\right)$, enthalpy change $\left(\Delta H_{\text {ads }}\right)$ and entropy change $\left(\Delta S_{\text {ads }}\right)$ of adsorption were determined from adsorption equilibrium constants at different temperatures. The values of thermodynamic parameters revealed that the adsorption of EV on UBTL was feasible, spontaneous and endothermic in nature leading to chemisorption. Again, the equilibrium amount adsorbed, calculated from pseudo-second order kinetic plots for different initial $\mathrm{pH}$ of solution was found to be minimum at neutral medium compared with acidic and basic media due to the amphoteric nature of Ethyl violet in aqueous solution and zero point charge of $\mathrm{pH}$ of UBTL.
\end{abstract}

Keywords: Ethyl Violet, Used Black Tea Leaves, Adsorption Kinetics, Isotherms, Thermodynamics

\section{Introduction}

Aquatic environment of developing countries are seriously polluted due to the rapid growth of dying, textile, ternary, paint/pigment, drugs industries. These industries are using synthetic dyes to color their products, and discharging a large amount of effluents into aquatic environment. Around 10,000 different types of dyes exist commercially [1]. Annually over $7 \times 105$ metric tons are available for industrial purposes and without prior treatment; $10-15 \%$ of the dyestuff entered the natural environment causes pollution [2-3]. Ethyl violet (EV) is a triphenylmethane dye which has extensive industrial applications [4]. In addition, the colored effluents have carcinogenic and highly toxic effect to living things [5]. Therefore, to remove dyes from wastewater and refresh the ambiance, it is necessary to develop effective method for practical application. In recent years, there are various conventional techniques, such as photocatalytic degradation $[6,7]$, chemical degradation [8, 9], flocculation [10], Biodegradation [11], nanofiltration [12], oxidation [13], etc. can be used successfully to improve water quality by removing dye from wastewater. However, several of these techniques have some kind of disadvantages. From the above mentioned techniques, adsorption is considered as an efficient and economical method for its easier operation procedure. Activated carbon is extensively employed as an 
effective adsorbent because of its high adsorption capacity. But activated carbon is a costly adsorbent and it produces secondary waste due to the difficulty in its regeneration process. Therefore, researchers are searching for low-cost and naturally occurring adsorbents $[14,15]$.

Different researchers reported several low cost adsorbents for the removal of ethyl violet dye, namely modified clays [16], wild carob forest wastes [17, 18], regenerated spent bleaching soil [19], etc. However, the adsorption capacity of the mentioned adsorbents is not sufficient to use; researchers are in search of new adsorbents with better capacity to improve adsorption performance.

Tea is a very common beverage drink in the world. After preparing of tea, by pouring hot or boiling water over cured or fresh leaves of tea (Camellia sinensis), produce waste materials in everywhere. The proper utilization of this used black tea leaves (UBTL) would make economical and environmental benefits. Several studies have been reported about the utilization of used black tea leaves as a biosorbent with high efficiency to eliminate organic dyes and heavy metals from water as well as from wastewater [20-29]. However, no research has been done to investigate the potential of Ethyl violet adsorption on UBTL.

In this study, the potential applicability of used black tea leaves as a biosorbent for the removal of Ethyl violet from aqueous solution was evaluated by investigating the kinetics and thermodynamics of adsorption of Ethyl violet on UBTL. The effects of dye concentration, processing temperature and $\mathrm{pH}$ of dye solution on kinetics were studied in batch experiments. Adsorption isotherm and thermodynamic parameters were estimated from the experimental data.

\section{Materials and Methods}

\subsection{Chemicals}

All chemicals used in this research work were analytical grade. Ethyl violet (EV) is a cationic triarylmethane synthetic dye. It is an ethyl homolog of crystal violet. IUPAC name of Ethyl violet is N-4-bis4-(diethylamino) phenylmethylene-2, 5-cyclohexadien-1-ylidene-N-ethyl-chloride. Its chemical formula is $\mathrm{C}_{31} \mathrm{H}_{42} \mathrm{ClN}_{3}$ having molecular weight $492.15 \mathrm{~g}$. Synonyms of Ethyl violet are Basic Blue 14, Basic violet, Ethyl purple, Ethyl violet G; Basic violet 4, Ethyl purple 6B, Ethyl violet $\mathrm{Cl}$ and its CI No. is 42600. The structural formula of Ethyl violet is shown Figure 1. Stock solution of $1000 \mathrm{mg} / \mathrm{L} \mathrm{EV}$ was prepared by dissolving required amount of Ethyl violet (EV) in distilled water and different concentrated EV solutions were prepared from its dilution. up to the mark to prepare stock solution. Low concentrated $\mathrm{NaOH}(0.01 \mathrm{M})$ or $\mathrm{HNO}_{3}(0.01 \mathrm{M})$ were used to adjust the $\mathrm{pH}$ of different solutions.

\subsection{Preparation and Characterization of Adsorbent}

Used black tea leaves (UBTL) as a biosorbent was prepared from fresh black tea leaves. At first, black tea leaves (BTL) were collected from a departmental store at Dhaka city in Bangladesh. Collected black tea leaves were boiled with distilled water for 2 hours and washed with distilled water for several times so that colored materials were removed from black tea leaves. Residual leaves were dried in room temperature and ultimately dried in an electric oven at $105^{\circ} \mathrm{C}$ for 12 hours and then sieved through the metallic sieves to obtain particle size $212-300 \mu \mathrm{m}$. It was then stored at room temperature in a desiccator until the experiment was conducted. For the characterization of surface morphology of UBTL, a very small amount of dried UBTL was taken on a sample holder and put in a Scanning Electron Microscope (SEM, JSM-6490LA, JEOL, Japan) and microgram was taken under high vacuum $\left(10^{-5}-10^{-6}\right.$ torr) using $20 \mathrm{KeV}$ at $\times 3,000$ magnification and presented in Figure 2 .

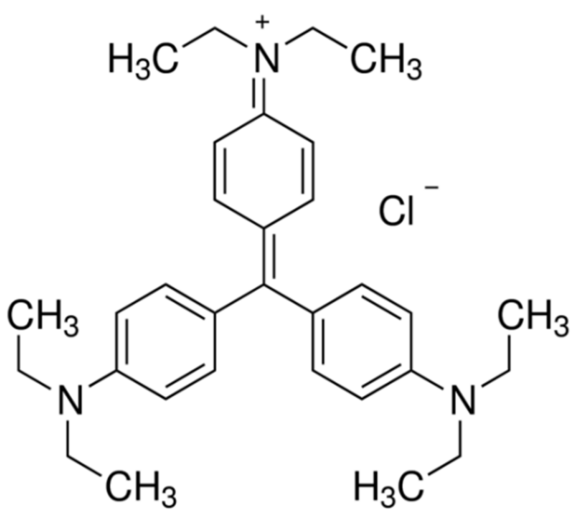

Figure 1. Molecular structure of Ethyl violet (EV).

\subsection{Experiments for Adsorption Kinetics}

Batch adsorption experiments were performed to investigate the effect of concentration, temperature and solution $\mathrm{pH}$ on adsorption kinetics.

\subsubsection{Effect of Concentration}

For kinetic studies, at first, $0.025 \mathrm{~g}$ of adsorbent (UBTL) was added with $25.0 \mathrm{~mL}$ of about $20 \mathrm{mg} / \mathrm{L} \mathrm{EV} \mathrm{solution} \mathrm{at} \mathrm{pH}$ 6.0. Then solution was shaken in a thermostatic mechanical shaker (NTS-4000 Eyela, Japan) at $35.0 \pm 0.2^{\circ} \mathrm{C}$. The mixtures were separated, after shaking of different time of intervals. The absorbance of separated solution with proper dilution and at $\mathrm{pH} 6.0$ was measured using a UV-vis spectrophotometer (Model-1800A, Shimadzu, Japan) at $\lambda_{\max } 595.50$ $\mathrm{nm}$ to determine the residual concentration of the EV dye in solution after different adsorption times. Again, the concentration of EV dye in initial solution was also determined by same procedure. Similar kinetic experiments were conducted using five different initial concentrations of EV solutions. The amounts adsorbed at different contact times for different initial concentrations were determined from the following equation (1),

$$
q_{t}=\frac{\left(C_{o}-C_{t}\right) V}{W}
$$

where, $C_{\mathrm{o}}$ is the initial concentration of $\mathrm{EV}(\mathrm{mg} / \mathrm{L}), C_{\mathrm{t}}$ is the concentration of $\mathrm{EV}$ at time $t(\mathrm{mg} / \mathrm{L}), q_{\mathrm{t}}$ is the amount 
adsorbed at time $t(\mathrm{mg} / \mathrm{g}), V$ is the volume of the solution (L) and $W$ is the mass of the adsorbent $(\mathrm{g})$.

\subsubsection{Effect of Temperature}

To determine the effect of temperature on adsorption kinetics, same kinetic experiments were performed at different temperatures for a fixed concentration of $\approx 100 \mathrm{mg} / \mathrm{L}$ of Ethyl violet solution at $\mathrm{pH}$ 6.0.

\subsubsection{Effect of $P H$}

Effect of $\mathrm{pH}$ of dye solution was investigated by implementing similar kinetic experiments at different $\mathrm{pH}$ of dye solution for a fixed concentration of $\approx 100 \mathrm{mg} / \mathrm{L}$ of Ethyl violet solution at constant temperature and other parameters were kept constant.

\section{Results and Discussion}

\subsection{Characterization of Adsorbent}

Prepared used black tea leave was characterized by Scanning Electron Microscope (SEM). Figure 2 presents the SEM microgram of prepared UBTL which shows some cavities on the UBTL surface as active sites to adsorb. Very small surface area and negligible amount of pore volume of UBTL were reported in our previous articles [20].

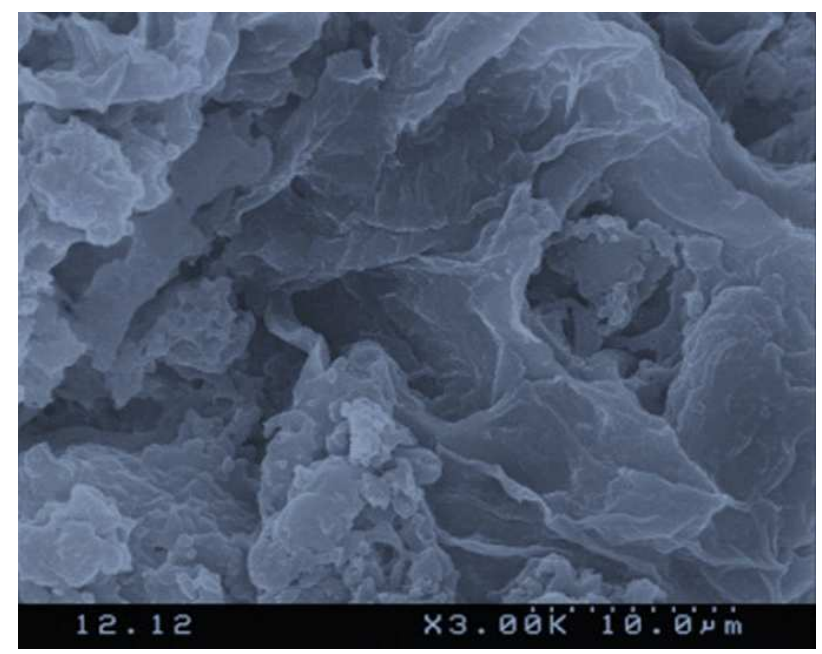

Figure 2. SEM micrograph of prepared UBTL $(\times 3000\}$.

\subsection{Effect of Concentration}

Concentration of dye is a very important parameter for adsorption kinetics. Figure 3 shows the variation of amount adsorbed of EV on UBTL with time for different initial concentrations of EV. The figure shows that for each concentration of dye, the amount adsorbed rapidly increased at the beginning then became gradually steady which is less significant for high concentrated solution of EV dye. This is due to the fact that, with the increase of initial dye concentration, the number of dye molecules increases in the medium, and which causes decrease of steric hindrance at the different adsorption sites [24, 25].
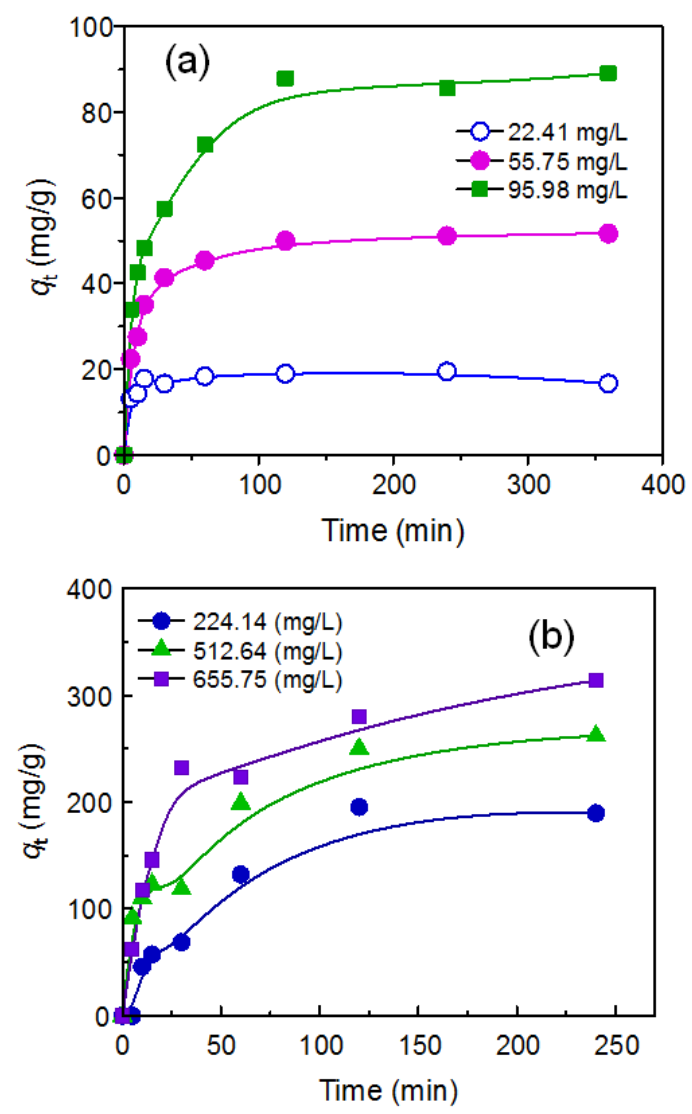

Figure 3. Variation of the amount adsorbed of EV on UBTL with time for different initial concentrations at pH 6.0 and at $35.0 \pm 0.2^{\circ} \mathrm{C}$.

\subsection{Kinetic Modeling of Adsorption}

Following kinetic models such as pseudo-first-order, pseudo-second-order, Elovic and Intra-particle diffusion models were applied to evaluate the adsorption dynamics of the process.

\subsubsection{Pseudo First-Order Kinetics}

Pseudo-first order kinetic equation was proposed by Lagergren [30] assuming that one active site on surface occupied with one adsorbate species. Literature review showed that many researchers applyed pseudo-first order kinetic equation to investigate adsorption kinetic data [31, $32]$. The linear form of this model expressed by the following relation (2),

$$
\log \left(q_{e}-q_{t}\right)=\log q_{e}-k_{1} t
$$

where, $q_{\mathrm{e}}$ is the adsorption capacity at equilibrium $(\mathrm{mg} / \mathrm{g}), q_{\mathrm{t}}$ is the adsorption capacity at time $t(\mathrm{mg} / \mathrm{g}), k_{1}$ is the rate constant for the pseudo-first-order $\left(\mathrm{min}^{-1}\right)$ kinetics. The plot of $\log \left(q_{\mathrm{e}}-q_{\mathrm{t}}\right)$ vs $t$ as presented in Figure 4 shows the validity of pseudo-first-order kinetics to the adsorption EV on UBTL for different initial concentrations. The figure reveals that each plot does not give straight line with the whole range of concentration indicating the failure of fitness of pseudo first order kinetics. 

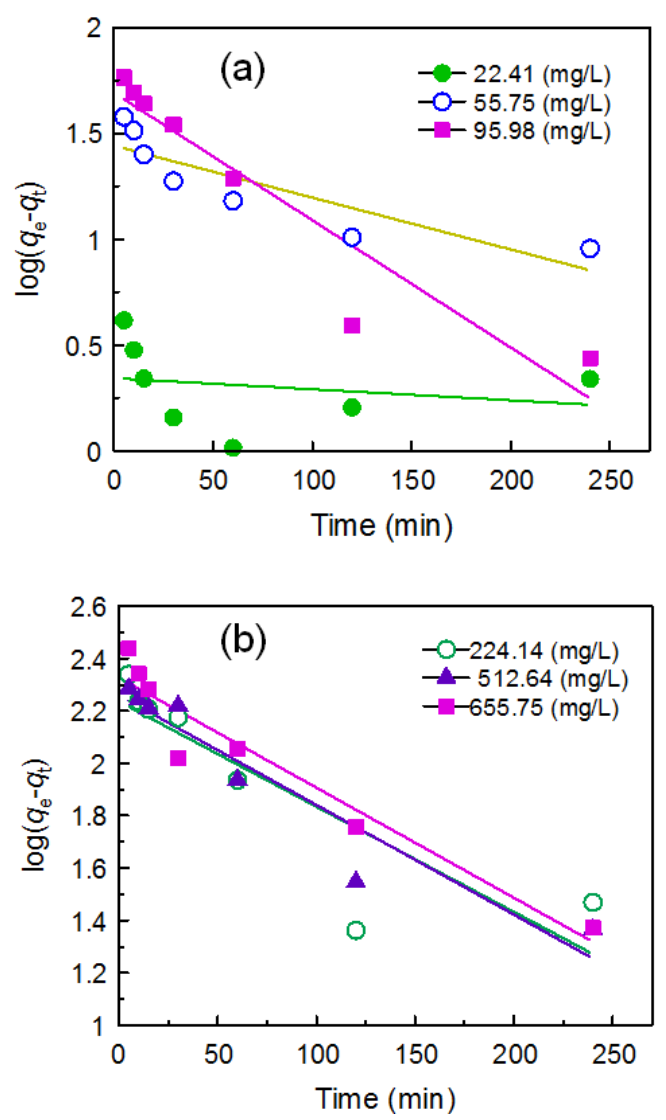

Figure 4. Pseudo-first order kinetic plot of the adsorption of EV on UBTL at pH 6.0 and $35.0 \pm 0.2^{\circ} \mathrm{C}$ for different initial concentrations.
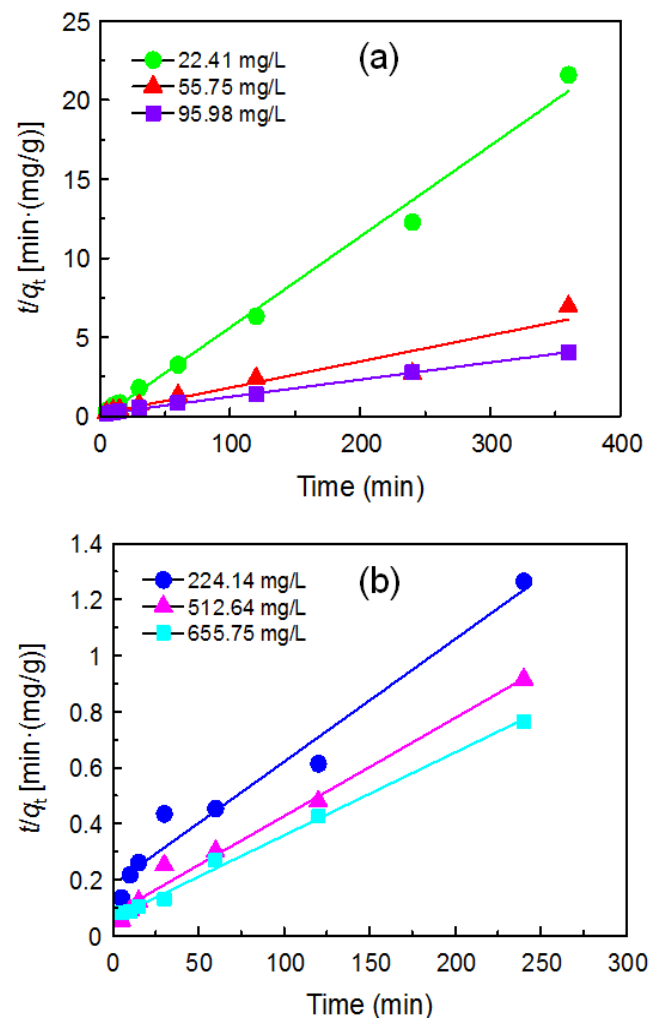

Figure 5. Pseudo second-order kinetic plot of the adsorption of EV on UBTL at $\mathrm{pH} 6.0$ and $35.0 \pm 0.2^{\circ} \mathrm{C}$ for different initial concentrations.

\subsubsection{Pseudo Second-Order Kinetics}

Ho and McKay's pseudo second order rate equation was developed based on the interaction of two active sites on surface with the adsorbates [32]. The linear form of the pseudo second-order kinetic model is expressed by the following equation (3):

$$
\frac{t}{q_{t}}=\frac{1}{k_{2} q_{e}^{2}}+\frac{t}{q_{e}}
$$

where, $q_{\mathrm{t}}$ is the amount adsorbed at time $t(\mathrm{mg} / \mathrm{g}), q_{e}$ is the equilibrium amount adsorbed $(\mathrm{mg} / \mathrm{g})$ and $k_{2}$ is the pseudo second order rate constant $(\mathrm{g} / \mathrm{mg} \mathrm{min})$. Figure 5 shows that the experimental data follow the pseudo second-order kinetic equation as a plot $t / q_{\mathrm{t}}$ vs $t$ for the whole range of experimental concentration with high values of regression coefficient $\left(R^{2}\right)$ given in Table 1. From the plots, the values of equilibrium amount adsorbed, equilibrium concentrations and pseudo second order rate constants were calculated for different initial concentrations of $\mathrm{EV}$ and the values are presented in Table 1.
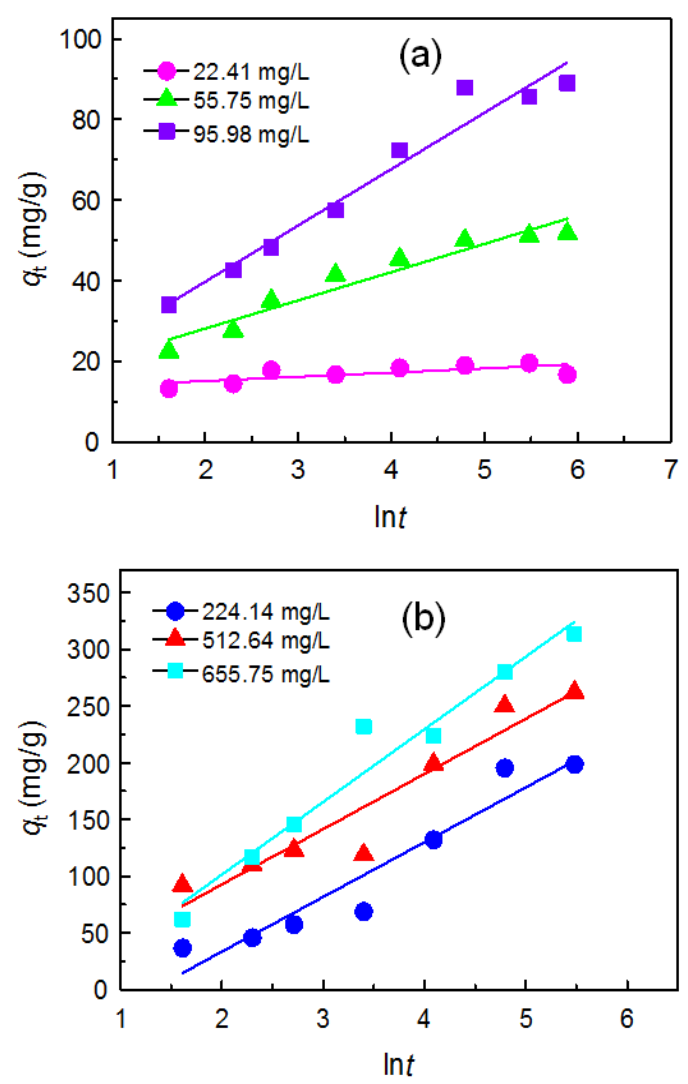

Figure 6. Plot of Elovich model for the adsorption of EV on UBTL at pH 6.0 and $35.0 \pm 0.2^{\circ} \mathrm{C}$ for different initial concentrations.

\subsubsection{Elovich Model}

Elovich equation used in several adsorption studies [32, 33 in the last few years to describe the adsorption kinetics. This model is described by the following linear equation (4),

$$
q_{\mathrm{t}}=\frac{1}{\beta} \ln (\alpha \beta)+\frac{1}{\beta} \ln t
$$


where, $q_{\mathrm{t}}$ is the amount adsorbed at time $t(\mathrm{mg} / \mathrm{g}), \alpha$ is the initial adsorption rate $(\mathrm{mg} / \mathrm{g}$. $\mathrm{min}), \beta$ is the adsorption constant $(\mathrm{g} / \mathrm{mg})$. The values of $\alpha$ and $\beta$ can be obtained with help of slope and intercept of the liner plot of $q_{\mathrm{t}} \mathrm{vs} \ln t$. Figure 6 shows the plot of $q_{\mathrm{t}}$ versus $\ln t$ which revealed that the adsorption of EV on UBTL does not follow the Elovich equation for different initial concentrations $\mathrm{EV}$ at $\mathrm{pH} 6.0$ and at $35 \pm 0.2^{\circ} \mathrm{C}$. Values of regression coefficient $\left(R^{2}\right)$ and respective parameters are given in Table 1.

\subsubsection{Intra-particle Diffusion Model}

Weber's intraparticle diffusion model is commonly used to investigate the transport mechanisms and rate controlling steps affecting the kinetics of adsorption [34]. Liner form of the intraparticle diffusion model can be represented by the following equation (5),

$$
q_{\mathrm{t}}=k_{\mathrm{id}} t^{\frac{1}{2}}+C
$$

where, $q_{\mathrm{t}}$ is the relative amount of dye adsorbed at time $t, k_{\mathrm{id}}$ is the intra particle particle constant, $C$ is the constant as the thickness of the boundary layer. The values of $k_{\text {id }}$ and $C$ can be calculated from the liner plot $q_{\mathrm{t}}$ vs $t^{1 / 2}$. Figure 7 shows the plot $q_{\mathrm{t}}$ versus $t^{1 / 2}$ which indicated that each of the straight line for different concentrations did not pass through the origin. The values of regression coefficient $\left(R^{2}\right)$ and respective parameters are presented in Table 1. From these observations, it can be said that other mechanism involved in the adsorption process along with the intra-particle diffusion model which is not the only rate controlling step [35].

The adsorption kinetics of EV on UBTL at pH 6.0 can be evaluated by comparing the regression factor values (given in Table 1) for the fitness of pseudo first-order, pseudo second order, Elovich and Intra-particle diffusion models. The low values of regression factor $\left(R^{2}\right)$ for the pseudo-first-order, Elovich and Intra-particle diffusion models show that these models poorly fitted with the experimental data on the tested dyes. On the other hand, the pseudo second-order model yielded the highest $R^{2}$ values of all tested models. For this reason, the pseudo second-order was found to be best describing the adsorption process of the present study.

Table 1. Different parameters deduced from the kinetic models.

\begin{tabular}{|c|c|c|c|c|c|c|c|c|c|c|c|c|}
\hline \multirow{2}{*}{$\begin{array}{l}\text { Conc. } \\
(\mathrm{mg} / \mathrm{L})\end{array}$} & \multicolumn{3}{|c|}{ Pseudo-first order } & \multicolumn{2}{|c|}{ Pseudo-second order } & \multicolumn{3}{|c|}{ Elovic model } & \multicolumn{4}{|c|}{ Intra-particle diffusion } \\
\hline & $k_{1} \times 10^{3}\left(\mathrm{~min}^{-1}\right)$ & $q_{\mathrm{e}}(\mathrm{mg} / \mathrm{g})$ & $R^{2}(-)$ & $k_{2}(\mathrm{~g} / \mathrm{mg} \cdot \min )$ & $q_{\mathrm{e}}(\mathrm{mg} / \mathrm{g})$ & $R^{2}(-)$ & $\alpha(\mathrm{mg} / \mathrm{g} \cdot \mathrm{min})$ & $B(\mathrm{~g} / \mathrm{mg})$ & $R^{2}(-)$ & $C$ & $k_{\text {id }}\left(\mathrm{mg} / \mathrm{g} \cdot \min ^{1 / 2}\right)$ & $R^{2}$ \\
\hline 22.41 & 13.0 & 8.356 & 0.048 & 0.0234 & 17.540 & 0.991 & 0.4140 & 0.958 & 0.528 & 15.24 & 0.201 & 0.310 \\
\hline 55.75 & 1.00 & 34.874 & 0.760 & 0.0017 & 62.50 & 0.919 & 10.023 & 0.143 & 0.932 & 27.16 & 1.581 & 0.794 \\
\hline 95.98 & 0.40 & 65.761 & 0.888 & 0.0007 & 100.00 & 0.998 & 12.352 & 0.072 & 0.959 & 36.87 & 3.272 & 0.831 \\
\hline 224.14 & 0.20 & 132.75 & 0.765 & 0.0003 & 250.00 & 0.966 & 13.357 & 0.021 & 0.918 & 7.275 & 13.98 & 0.918 \\
\hline 512.64 & 0.07 & 196.34 & 0.914 & 0.0001 & 285.21 & 0.986 & 21.025 & 0.02 & 0.913 & 66.20 & 14.12 & 0.914 \\
\hline 655.75 & 0.05 & 243.76 & 0.927 & 0.0001 & 333.33 & 0.996 & 73.225 & 0.016 & 0.956 & 74.90 & 17.37 & 0.838 \\
\hline
\end{tabular}
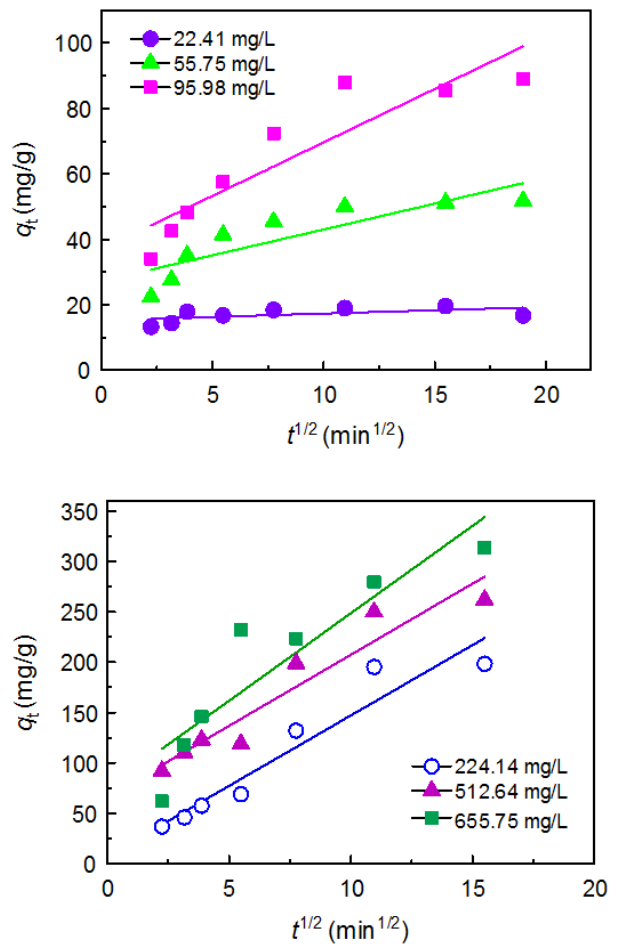

Figure 7. Intra-particle diffusion model plot of the adsorption of EV on UBTL at $p H 6.0$ and $35.0 \pm 0.2^{\circ} \mathrm{C}$ for different initial concentrations.

\subsection{Adsorption Isotherm}

The equilibrium amounts adsorbed and respective equilibrium concentrations were calculated from the well fitted pseudo second-order kinetic plots (Figure 5) to construct the adsorption isotherm. Figure 8 shows the adsorption isotherm. of EV on UBTL at $\mathrm{pH} 6.0$ and $35.0 \pm 0.2^{\circ} \mathrm{C}$ which was evaluated using different isotherm model equations such as Langmuir, Freundlich and Temkin models.

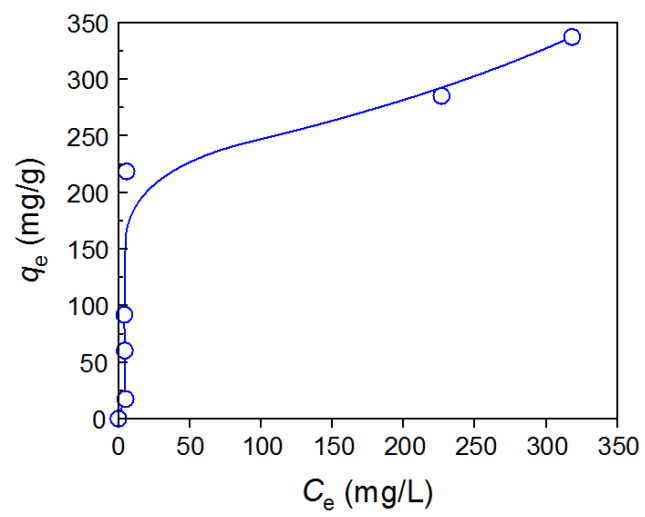

Figure 8. Adsorption isotherm of EV on UBTL at pH 6.0 and at $35.0 \pm 0.2^{\circ} \mathrm{C}$.

\subsubsection{Langmuir Isotherm}

The linear form of Langmuir isotherm [36, 37] is given by 
the following equation (6),

$$
\frac{C_{\mathrm{e}}}{q_{\mathrm{e}}}=\frac{1}{q_{\mathrm{m}} b}+\frac{C_{\mathrm{e}}}{q_{\mathrm{m}}}
$$

where, Ce is the equilibrium concentration $(\mathrm{mg} / \mathrm{L})$, qe is the amount adsorbed at equilibrium $(\mathrm{mg} / \mathrm{g}), \mathrm{qm}$ is the monolayer adsorption capacity $(\mathrm{mg} / \mathrm{g})$ and $\mathrm{b}$ is the Langmuir constant (L/mg). Figure 9 shows the linear plot of Ce/qe against $\mathrm{Ce}$ as the Langmuir adsorption isotherm of EV on UBTL and from which the value of $q_{\mathrm{m}}$ was calculated to be $91.82 \mathrm{mg} / \mathrm{g}$ at $35.0 \pm 0.2^{\circ} \mathrm{C}$.

\subsubsection{Freundlich Isotherm}

An empirical relationship was developed by Freundlich $[38,39]$ for heterogeneous surface showing the variation of adsorption with equilibrium concentration mathematically which is given by the linear equation (7),

$$
\ln q_{\mathrm{e}}=\ln K_{\mathrm{F}}+\frac{1}{n} \ln C_{\mathrm{e}}
$$

where, $q_{\mathrm{e}}$ is the amount adsorbed per gram of adsorbent, $(\mathrm{mg} / \mathrm{g}), \mathrm{C}_{\mathrm{e}}$ is the equilibrium concentration $(\mathrm{mg} / \mathrm{L})$ and $K_{\mathrm{F}}$ and $1 / n$ is the Freundlich contant, characteristics of the solution and the adsorbent. Figure 10 shows the Freundlich isotherm as a plot of $\ln q_{\mathrm{e}} \mathrm{vs} \ln C_{\mathrm{e}}$ which is deviated from its linearity.

\subsubsection{Temkin Isotherm}

Temkin isotherm assumes that due to adsorbent-adsorbate interaction, the heat of adsorption of all the molecules in the layer would decrease linearly with coverage. Temkin model is expressed by the given linear equation (8) [40, 41],

$$
q_{\mathrm{t}}=B \ln K_{\mathrm{T}}+B \ln C_{\mathrm{e}}
$$

where, $B=R T / b_{T}$ is the constant related to adsorption energy, $R$ is the molar gas constant $(8.314 \mathrm{~J} / \mathrm{mol}), T$ is the temperature $(\mathrm{K}), b_{\mathrm{T}}$ is the adsorption potential $(\mathrm{J} / \mathrm{mol})$ and $K_{\mathrm{T}}$ is the constant equilibrium bond $(\mathrm{L} / \mathrm{g})$. Figure 11 shows the plot of $q_{\mathrm{e}} \mathrm{vs} \ln C_{\mathrm{e}}$ as the Temkin isotherm where data also deviated from its linearity.

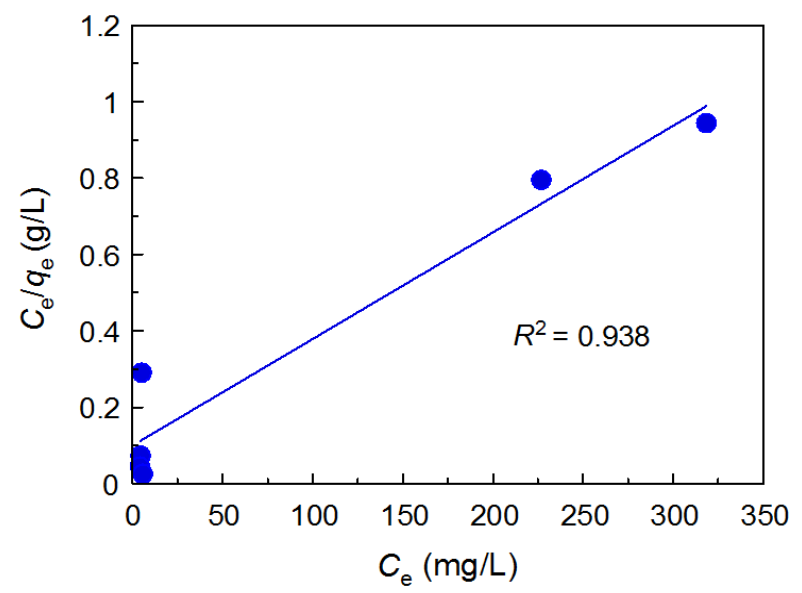

Figure 9. Langmuir isotherm of EV adsorption on UBTL.

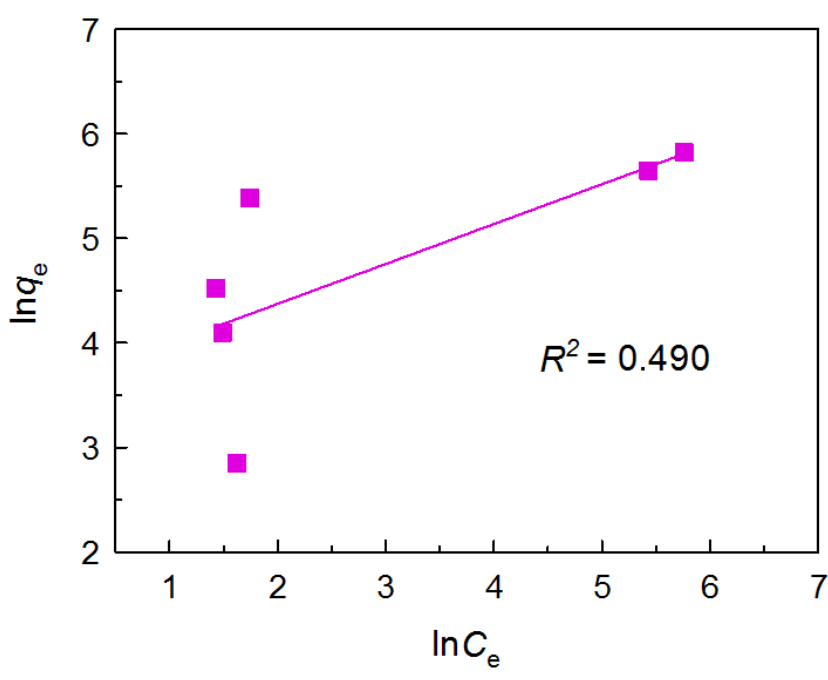

Figure 10. Freundlich isotherm of EV adsorption on UBTL.

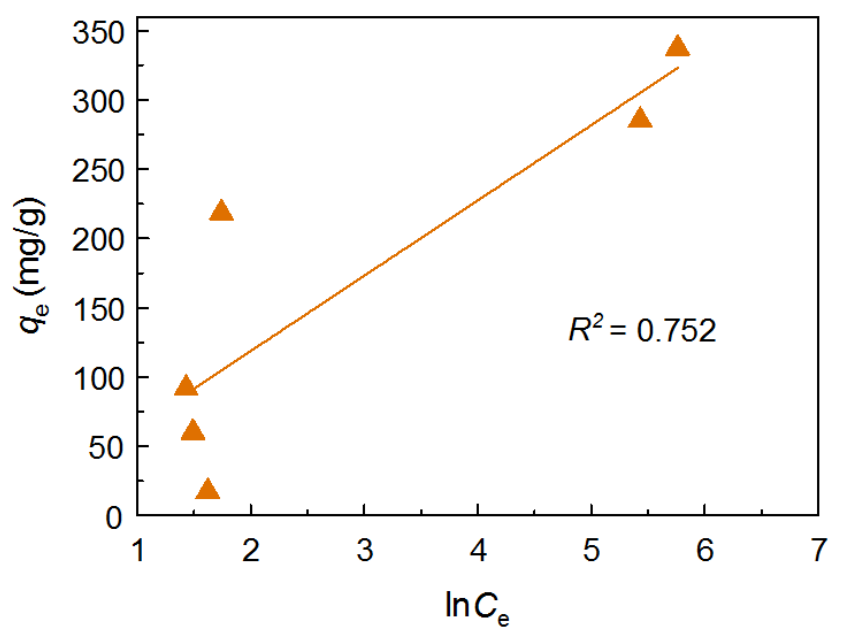

Figure 11. Temkin isotherm of EV adsorption on UBTL.

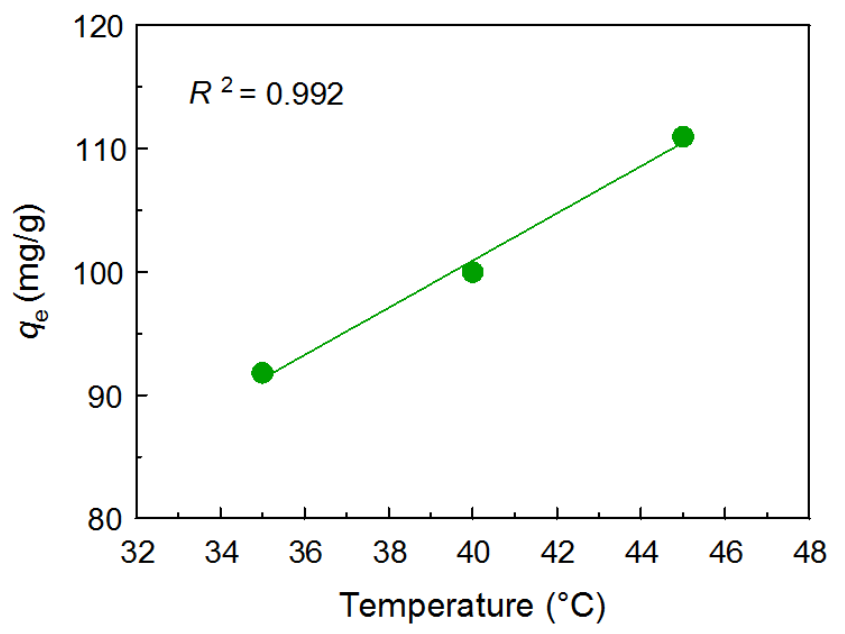

Figure 12. Variation of equilibrium amount adsorbed with temperature for adsorption of EV on UBTL.

Comparing the regression coefficient $\left(R^{2}\right)$, it is clear that the Langmuir equation $\left(R^{2}=0.938\right)$, is better to describe the adsorption behavior of EV onto UBTL from aqueous solution then Freundlich and Temkin equations. 


\subsection{Effect of Temperature}

To investigate the effect of temperature on the adsorption process, kinetic experiments were carried out at different temperatures in the range of 35 to $45{ }^{\circ} \mathrm{C}$ with same initial concentration of dye. Amounts adsorbed were calculated by applying pseudo second order equation (Figure. not shown) and values are plotted against temperature as shown in Figure 12. The results shown that the adsorption capacity is increases with increase of temperature suggested endothermic nature of the adsorption.

\subsection{Adsorption Thermodynamics}

Investigation of thermodynamic parameters are very important to evaluation of the feasibility of the adsorption process. Various thermodynamic parameters such as free energy change, enthalpy change and entropy change of adsorption can be estimated with the help of equilibrium constants at different temperatures [42-44]. The free energy change of the adsorption was determined using following equation (9),

$$
\Delta G_{a d s}=-R T \ln K_{C}
$$

where, $\Delta G_{\text {ads }}$ is the free energy change of adsorption $(\mathrm{kJ} / \mathrm{mol}), R$ is the molar gas constant $(8.314 \mathrm{~J} / \mathrm{mol} . \mathrm{K}), T$ is the absolute temperature $\left({ }^{\circ} \mathrm{K}\right), K_{\mathrm{c}}$ is the equilkibrium constant $\left(C_{\mathrm{a}} / C_{\mathrm{e}}\right), C_{\mathrm{a}}$ is the equilibrium concentration of $\mathrm{EV}$ on UBTL surface $(\mathrm{mg} / \mathrm{L})$ and $C_{\mathrm{e}}$ is the equilibrium concentration of the $\mathrm{EV}$ in solution $(\mathrm{mg} / \mathrm{L})$.

To obtain the values of enthalpy change $\left(\Delta H_{\mathrm{ads}}\right)$ and entropy change $\left(\Delta S_{\text {ads }}\right)$ of adsorption, the following equation (10) was applied [44]:

$$
\ln K_{C}=\frac{\Delta S_{a d s}}{R}-\frac{\Delta H_{a d s}}{R T}
$$

The values of $\Delta$ Hads and $\Delta$ Sads were deduced from slope and intercept of the linear plot of $\operatorname{lnKc}$ vs $1 / \mathrm{T}$ as shown in Figure 13. Estimated values of $\Delta \mathrm{Gads}, \Delta \mathrm{Hads}$ and $\Delta$ Sads are enlisted in Table 2 . The negative values of $\Delta$ Gads assured the spontanity of the adsorption of EV on UBTL and also the feasibility of the method. The positive value of $\Delta$ Hads implies that the adsorption of ethyl violet onto the UBTL is endothermic in nature. During the adsorption of EV onto UBTL, an increasing randomness appears at the solid-solution interface due to positive value of entropy change, $\Delta S_{\text {ads }}$. Bouguettoucha et al. also obtained similar results for the same dye onto wild carob forest wastes [17].

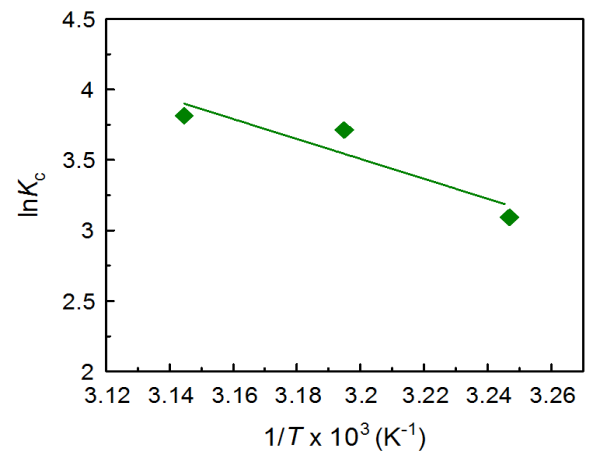

Figure 13. A plot of $\ln K_{c}$ vs $1 / T$ for the determination of thermodynamic parameter during the adsorption of EV on UBTL.

\subsection{Effect of $P H$}

The $\mathrm{pH}$ of the solution affects not only the adsorption capacity, but also the color and solubility of dye solutions. For this reason, $\mathrm{pH}$ is a master variable for adsorption studies [45]. To investigate the effect of $\mathrm{pH}$, a series of adsorption kinetic experiments were performed at different $\mathrm{pH}$ of $\mathrm{EV}$ dye solution. The changes of amount adsorbed with time at different $\mathrm{pH}$ are shown in the Figure 14. The equilibrium amounts of EV dye adsorbed on UBTL at different $\mathrm{pH}$ of the EV dye solutions were determined from the well fitted pseudo second order kinetic plots. In the variation of equilibrium amount adsorbed of EV dye with $\mathrm{pH}$ in Figure 15 reveals that the adsorption capacity of UBTL to ethyl violet from aqueous solution takes place maximum at basic condition $(\mathrm{pH} 8.0)$ or at acidic condition ( $\mathrm{pH} 4.0$ ), whereas minimum adsorption occurs at $\mathrm{pH} 6.0$ or neutral condition. At acidic condition, UBTL surface becomes positive by photonation $\left(\mathrm{H}^{+}\right)$which would be interacted with lone pair electrons of two nitrogen atoms in EV molecules, leading to high adsorption. Alternatively, at basic condition, UBTL surface becomes negative by de-photonation $\left(\mathrm{OH}^{-}\right)$which would be interacted with the one nitrogen atom contained positive charge $\mathrm{EV}$ molecules, leading to high adsorption than that at $\mathrm{pH} 6.0$ which could be occurs by dipole-dipole interaction or chemical bond formation. These observations might be due to the amphoteric nature of ethyl violet in aqueous solution and zero point charge of $\mathrm{pH}$ of UBTL [20, 21]. Such observations are in good agreement with earlier findings for the adsorption of same dye onto regenerated spent bleaching earth or the adsorption of methylene blue on kaolinite $[19,46]$. It is evident from the literature [47] that with increasing $\mathrm{pH}$ values, loss of $\mathrm{H}^{+}$ions occurs from the surface of adsorbent causes higher percentage of dye removal from aqueous solution at higher values of the $\mathrm{pH}$.

Table 2. Adsorption equilibrium constant and thermodynamic parameters for EV adsorption on UBTL at different temperatures.

\begin{tabular}{llllllll}
\hline $\boldsymbol{T}(\mathbf{K})$ & $\boldsymbol{C}_{\mathbf{a}}(\mathbf{m g} / \mathbf{L})$ & $\boldsymbol{C}_{\mathrm{e}}(\mathbf{m g} / \mathbf{L})$ & $\boldsymbol{K}_{\mathrm{c}=}\left(\boldsymbol{C}_{\mathrm{a}} / \boldsymbol{C}_{\mathrm{e}}\right)$ & $\boldsymbol{I n} \boldsymbol{K}_{\boldsymbol{c}}(-)$ & $\Delta \boldsymbol{H}_{\text {ads }}(\mathbf{k J} / \mathbf{m o l})$ & $\Delta \boldsymbol{G}_{\text {ads }}(\mathbf{k J} / \mathbf{m o l})$ & $\Delta \boldsymbol{S}_{\text {ads }}(\mathbf{k J} /\{\mathbf{m o l} \cdot \mathbf{K}\})$ \\
\hline 298 & 91.816 & 4.164 & 22.052 & 3.093 & & -8.856 & \\
303 & 95.371 & 2.329 & 40.944 & 3.712 & +58.83 & -9.002 & +0.217 \\
313 & 94.466 & 2.084 & 45.334 & 3.814 & & -9.148 & \\
\hline
\end{tabular}




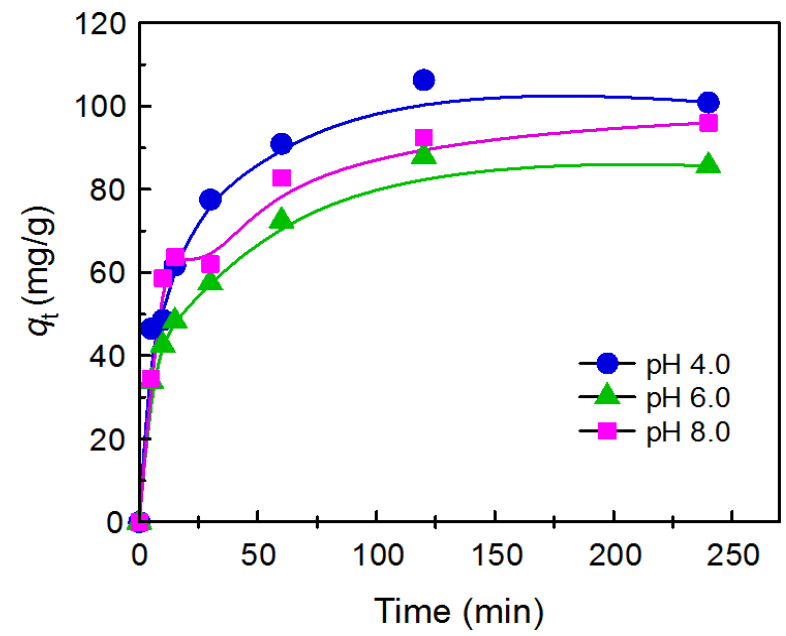

Figure 14. Variation of the amount adsorbed of EV on UBTL with time for different $p H$ of $E V$ solution of $100 \mathrm{mg} / \mathrm{L}$ at $35.0 \pm 0.2^{\circ} \mathrm{C}$.

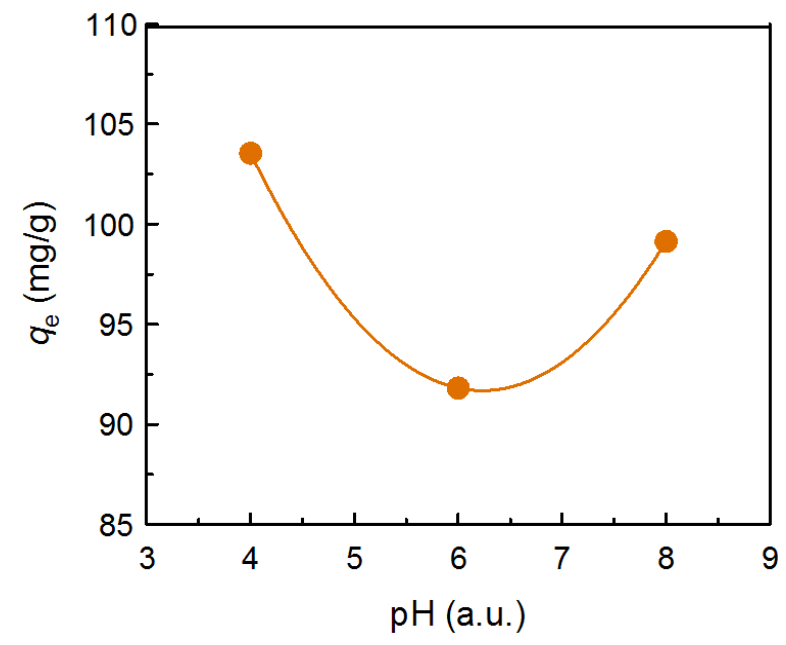

Figure 15. Variation of equilibrium amount absorbed with $\mathrm{pH}$ for the absorption of EV on UBTL at $35.0 \pm 0.2^{\circ} \mathrm{C}$.

\section{Conclusions}

The present investigation explores the feasibility of used black tea leaves as a biosorbent to remediate Ethyl violet dye from aqueous solution in a batch process. The modeling of the adsorption kinetics reveals to the best fit of pseudo second-order kinetic equation. Adsorption isotherm of $\mathrm{EV}$ on UBTL is well expressed by Langmuir model. The feasibility, spontaneity and also the endothermic nature of the adsorption process were affirmed by the finding values of the thermodynamic parameters. Furthermore, the amount adsorbed was found to be minimum at $\mathrm{pH} 6.0$ compared with acidic and basic conditions.

\section{Acknowledgements}

The authors would like to thank to the department of Chemistry, University of Dhaka for given facilities to perform this research work.

\section{References}

[1] Zhou Y., Ge L., Fan N. \& Xia M. (2018). Adsorption of Congo red from aqueous solution onto shrimp shell powder. Adsorption Science and Technology, 8 DOI: $10.1177 / 0263617418768945$.

[2] Sharma R., Satsangee S. P. and Verma S. K. (2021). Raw, activated and modified biosorbents for the speciation of C. I. acid red 2 from aqueous solutions: An adsorption study. Int. J. Water Res. Environ. Eng., 13 (1): 1-19.

[3] Reza K. M., Kurny A., Gulshan F. (2017). Parameters affecting the photocatalytic degradation of dyes using TiO2: A review. Appl. Water Sci., 7: 1569-1578.

[4] Chen C. Y., Yen S. H. and Chung Y. C. (2014). Combination of photoreactor and packed bed bioreactor for the removal of Ethyl Violet from wastewater. Chemosphere, 117: 94-501.

[5] Alene A. N., Abate G. Y. and Habte A. T. (2020). Bioadsorption of Basic Blue dye from aqueous solution onto raw and modified waste ash as economical alternative bioadsorbent. J. of Chem., 1-11.

[6] Lee W. L. W., Lu C. S., Lin H. P., Chen J. Y. and Chen C. C. (2014). Photocatalytic degradation of ethyl violet dye mediated by $\mathrm{TiO}_{2}$ under an anaerobic condition. J. Taiwan Inst. Chem. Eng. 45: 2469-2479.

[7] Wang J., Zhang G., Zhang Z., Zhang X., Zhao G., Wen F., Pan Z., Li Y., Zhang P. and Kang P. (2006). Investigation on photocatalytic degradation of ethyl violet dyestuff using visible light in the presence of ordinary rutile $\mathrm{TiO}_{2}$ catalyst doped with upconversion luminescence agent. Water Res., 40 (11): 2143-2150.

[8] Abdi M., Balagabri M., Karimi H., Hossini H. and Rastegar S. O. (2020). Degradation of crystal violet (CV) from aqueous solutions using ozone, peroxone, electroperoxone, and electrolysis processes: a comparison study.

[9] Al-Shihri A. S. and El-Assy N. B. (2003). The degradations of Ethyl Violet dye solution by gamma radiation. JKAU: Sci., 15: 99-114.

[10] Liu Z., Xu D., Xia N., Zhao X., Kong F., Wang S. and Fatehi P. (2018). Preparation and application of phosphorylated xylan as a flocculant for cationic Ethyl Violet dye. Polymers, 10: 317-332.

[11] Azmi W., Sani R. K. and Banerjee U. C. (1998). Biodegradation of triphenylmethane dyes. Enzyme Microb. Technol. 22: 185-191.

[12] Liu M., Chen Q., Lu K., Huang W., Lü Z., Zhou C., Yu S. and Gao C. (2017). High efficient removal of dyes from aqueous solution through nanofiltration using diethanolamine-modified polyamide thin-film composite membrane. Sep. Purif., 173: 135-143.

[13] Soares P. A., Souza R., Soler J., Silva T. F. C. V., Souza S. M. A. G. U., Boaventura R. A. R. and Vilar V. J. P. (2017). Remediation of a synthetic textile wastewater from polyestercotton dyeing combining biological and photochemical oxidation processes. Sep. Purif. Technol., 172: 450-462. 
[14] Odiongenyi A. O. (2019). Removal of Ethyl Violet dye from aqueous solution by graphite dust and nano graphene oxide synthesized from graphite dust. Comm. In Phy. Sci., 4 (2): 103-109.

[15] Ahmed, R., Kumar, L. and Hossain, M. A. (2018). Kinetics and thermodynamics of adsorption for removal of Basic Violet 14 by used black tea leaves from aqueous solution. NUB J. of App. Sci., 2 (1\&2): 39-46.

[16] Ullah R., Iftikhar F. J., Ajmal M., Shah A., Akhter M. S., Ullah H. and Waseem A. (2020). Modified clays as an efficient adsorbent for brilliant green, Ethyl Violet and allura red dyes: Kinetic and thermodynamic studies. Pol. J. Environ. Stud., 29 (5): 3831-3839.

[17] Bouguettoucha A., Reffas A., Chebli D. and Amrane A. (2017). Adsorption of the cationic dye Ethyl Violet on acid and alkali-treated wild carob powder, a low-cost adsorbent derived from forest waste. Iran. J. Chem. Chem. Eng., 36 (1): 87-96.

[18] Bouguettoucha A. (2015). Adsorption of Ethyl Violet dye in aqueous solution by forest wastes, wild carob. Des. And water Treat. 57 (4): 1-12.

[19] Tsai W. T., Chang Y. M., Lai C. W. and Lo, C. C. (2005). Adsorption of Ethyl Violet dye in aqueous solution by regenerated spent bleaching earth. J Colloid Interf. Sci. 289 (2): 333-338.

[20] Hossain, M. A., (2006). Study on process development for removal of $\mathrm{Cr}(\mathrm{VI})$ from wastewater by sorption on used black tea leaves, Ph. D. Thesis, Kanazawa University, Japan.

[21] Hossain, M. A., Kumita, M., Michigami, Y. and Mori, S. (2005). Optimization of parameters for $\mathrm{Cr}(\mathrm{VI})$ adsorption on used black tea leaves, Adsorption, 11, 555-564.

[22] Islam, T. S. A., Begum, H. A., Hossain, M. A. and Rahman, M. T. (2009). Removal of $\mathrm{Pb}$ (II) from aqueous solution by sorption on used tea leaves, J. Bangladesh Acad. Sci. 33 (2), 167-178.

[23] Hossain, M. A., Kumita, M. and Mori, S. (2010). SEM characterization of the mass transfer of $\mathrm{Cr}(\mathrm{VI})$ during the adsorption on used black tea leaves, African J Pure and Appl. Chem. 4 (7), 135-141.

[24] Hossain, M. A., Kumita, M. and Mori, S. (2017). Investigation of the removal characteristics of $\mathrm{Cr}(\mathrm{VI})$ by used black tea leaves from aqueous system, J. Chem. and Mater. Res. 6 (2-3), 31-36.

[25] Hossain, M. A., Hasan, T. A. and Hossain, M. L. (2015). Adsorption of Crystal Violet on used black tea leaves from acidic solution: equilibrium, thermodynamic and mechanism studies, Int. J. Sci, 4 (10), 31-39.

[26] Hossain, M. A. and Hossain, M. L. (2014). Kinetic study of Malachite Green adsorption on used black tea leaves from aqueous solution, Int. J. Adv. Res. 2 (4), 360-374, 2014.

[27] Hossain, M. A. and Mohibullah, M. (2017). Kinetics and thermo-dynamics of adsorption of Basic Blue 41 on used black tea leaves, Int. J. Sci. \& Engr. Res. 8 (4), 995-1002.

[28] Hasan, M. T. A., Hossain, M. L. and Hossain, M. A. (2017). Mechanism of Basic Violet 3 adsorption on used black tea leaves from neutral solution, Int. J. Scientific \& Engineering Res. 8 (10), 1047-1055.
[29] Hossain, M. A., Ali, M. M. and Islam, T. S. A. (2018). Comparative adsorption of Methylene Blue on different low cost adsorbents by continuous column process, International Letters of Chemistry, Physics and Astronomy. 77, 26-34.

[30] Lagergren, S. (1898). About the theory of so called adsorption of soluble substances, Kungliga svenska vertenskapsakademiens. Handlinger, 24 (4): 1-39.

[31] Jeddou K. B., Bouaziz F., Taheur F. B., Nouri-Ellouz O., Ellouz-Ghorbel R. and Ellouz-Chaabouni S. (2021). Adsorptive removal of direct red 80 and methylene blue from aqueous solution by potato peels: a comparison of anionic and cationic dyes. Water Sci. \& Technol., 83 (6): 1384-1398.

[32] Hossain M. A. and Ahmed, R. (2015). Kinetics and thermodynamics of adsorption for the Removal of Fast Green by Used black tea leaves from aquatic environment. British J. of Environ. Sci., 3 (5): 32-44.

[33] Alhujaily A., Yu H., Zhang X. and Ma, F. (2020). Adsorptive removal of anionic dyes from aqueous solutions using spent mushroom waste. App. Water Sci., 10 (183): 1-12.

[34] Munilakshm N., Srimuralia M. and Karthikeyana, J. (2013). Adsorptive removal of Acid Red 1, from aqueous solutions by preformed flocs. Int. J. of Current Eng. and Technol., 3 (4): 1456-1462.

[35] Jain S. N. and Gogate P. R. (2017). Adsorptive removal of Acid violet 17 dye from wastewater using biosorbent obtained from $\mathrm{NaOH}$ and $\mathrm{H}_{2} \mathrm{SO}_{4}$ activation of fallen leaves of Ficus racemosa. J. Mol. Liq., 243: 132-143.

[36] Langmuir I. (1918). Adsorption of gases on glass, mica, and platinum. J. Am. Chem. Soc., 40: 1361-1403.

[37] Santhi T., Manonmani S. and Smitha T. (2010a). Removal of malachite green from aqueous solution by activated carbon prepared from the epicarp of Ricinus communis by adsorption. J. Hazard. Mat., 179: 178.

[38] Freundlich H. (1907). Adsorption in solution. Zeitschrift f'ur Physikalische, Chemie. 57: 385-470.

[39] Koyuncu H. and Kul A. R. (2020). Removal of methylene blue dye from aqueous solution by nonliving lichen (Pseudevernia furfuracea (L.) Zopf.), as a novel biosorbent. App. Water Sci., 10 (72): 1-14.

[40] Temkin M. J. and Pyzhev V. (1940). Recent modi-fications to Langmuir isotherms: Kinetics of ammonia synthesis on promoted iron catalysts. ActaPhysiochim, URSS, 12: 217222 .

[41] Raphaël D., Massaï H., Bagamla W. and Talami B. (2020). Study of the adsorption of Methylene Blue and Tartrazine in aqueous solution by local materials of cameroonian origin. Am. J. Phy. Chem., 9 (3): 45-51.

[42] Singh A., Sonal S., Kumar R. and Mishra B. K. (2019). Adsorption of chlorhexidine digluconate on acid-modified fly ash: Kinetics, isotherms and influencing factors. Environ. Eng. Res., 25: 205-211.

[43] Boparai K. H., Joseph M. and O'carroll M. D. (2011). Kinetics and thermodynamics of cadmium ion removal by adsorption onto nanozerovalent iron particles. J. Hazard. Mat., 186 (1): 458-465. 
[44] Srilakshmi C. and Saraf, R. (2016). Ag-doped hydroxyapatite as efficient adsorbent for removal of Congo Red dye from aqueous solution: synthesis, kinetic and equilibrium adsorption isotherm analysis. Microporous Mesoporous Mater., 219: 134-144.

[45] Ozacar M. and Sengil I. A. (2003). Adsorption of reactive dyes on calcined alunite from aqueous solution. J. of Hazard. Mat., 98: 211-224.
[46] Ghosh D. and Bhattacharyya K. G. (2002). Appl. Clay Sci., 20: 295 .

[47] Chakraborty S., Mukherjee A., Das S., Maddela N. R., Iram S. and Das P. (2021). Study on isotherm, kinetics, and thermodynamics of adsorption of crystal violet dye by calcium oxide modified fly ash. Environ. Eng. Res., 26 (1): 1-9. 